\title{
Variação e aquisição da flexão nominal e da flexão verbal
}

Christina Abreu Gomes (UFRJ)

Márcia Cristina Vieira Pontes (mestre em Lingüística/UFRJ)

Miriam Cristina Severino Almeida (mestranda em Lingüística/UFRJ)

Ana Cristina Baptista de Abreu (mestranda em Lingüística/UFRJ)

Recebido 20, jan. 2011/Aprovado, 7 mar. 2011

\section{Resumo}

Dados de produção espontânea de crianças entre 1;11 e 5;0 foram coletados da amostra AQUIVAR-PEUL/UFRJ e analisados em função do seu caráter de variável sociolinguística e de processo desenvolvimental. Neste artigo abordamos a questão da relação entre conhecimento linguístico, variação e aquisição com base em dados de aquisição da flexão variável em nominais e em verbos. Os resultados de flexão verbal revelaram que os condicionamentos observados para a comunidade adulta se manifestaram gradualmente indicando uma aquisição gradual dos mesmos. A mesma situação não foi observada para os dados de flexão nominal. São discutidas as implicações desses resultados.

Palavras-chave: variação, aquisição, flexão nominal, flexão verbal. 


\section{Introdução}

Estudos sobre aquisição da variação sociolinguística não são muito numerosos. Há diversas razões para isso. De um lado, a aquisição tem sido abordada em quadros teóricos que excluem a variação do escopo da gramática. De outro, mesmo dentro dos estudos variacionistas a aquisição não teve lugar de destaque. Roberts (2002, p. 333-334) aponta algumas das razões para que os estudos variacionistas não tenham focalizado a fala das crianças. Um deles é o próprio fato de ser um campo recente de investigação, tendo como origem a dialetologia, que tem um enfoque em dados de adultos. Além disso, as crianças são vistas como as que adquirem o dialeto e não as responsáveis por sua manutenção e mudança.

Embora alguns estudos sociolinguísticos tenham focalizado a fala de crianças, e discutido a importância das crianças no processo de mudança, esses estudos foram esparsos nas duas primeiras décadas de trabalho variacionista (FISCHER, 1958; ROMAINE, 1978; REID, 1978; KOVAC e ADAMSON, 1981, para citar alguns). Mais recentemente a variação sociolinguística e a importância de sua aquisição mereceram maior destaque na discussão da natureza do conhecimento linguístico. Diversos estudos, desenvolvidos principalmente a partir do final da década de 90 , têm demonstrado a importância de crianças e adolescentes na transmissão de padrões sociolinguísticos tanto em comunidades de fala estáveis (ECKERT, 1988; KERSWILL, 1996; BRITAIN, 1997) como na formação de novos dialetos (KERSWILL \& WILLIAMS, 2000). Roberts (1996, 2002). Docherty et al. (2006) e Foulkes et al. (2005) demonstraram que as crianças refletem o condicionamento observado para os adultos já aos 2 anos de idade.

Propostas teóricas recentes têm defendido a proposição inicial de Labov de que a gramática é dotada de heterogeneidade sistemática refletida no desempenho variável dos falantes (WEINREICH, LABOV, HERZOG, 1968). Bod, Hay e Jannedy (2003, p. 2-3) explicitamente defendem que o conhecimento da variação deve ser entendido como parte da competência do falante uma vez que os falantes utilizam as variantes para codificar informação linguística e extralinguística. Assim, o conhecimento sobre a variação indexada não deve ser colocada aparte dos outros tipos de conhecimento linguístico. Docherty e Foulkes (2000, p. 110-111), por exemplo, apontam para o fato de que não há como diferenciar, no período aquisitivo, aquisição de conhecimento fonológico que envolve oposição distintiva daquele relacionado a aspectos da identidade sociolinguística do falante e que o resultado da aquisição implica que o falante adquiriu também uma identidade (sócio)dialetal juntamente com os aspectos estruturais. Guy e Boyd (1990) mostraram que a aquisição dos condicionamentos da realização variável de $-\mathrm{t},-\mathrm{d}(-\mathrm{t},-\mathrm{d}$ deletion) 
está associada à aquisição de aspectos da gramática. Observando dados de falantes entre 4 e 65 anos, os autores concluíram que a aquisição do condicionamento da realização variável de $-\mathrm{t} e-\mathrm{d}$ em verbos irregulares, como slept, é um longo processo em que as crianças mais novas demonstram não ter sequer esta consoante representada, uma vez que a ausência é categórica, e que crianças mais velhas e alguns adultos parecem analisar estas formas como os itens em que as oclusivas dentais não têm status morfológico, como em cent. Portanto, a aquisição do condicionamento variável que envolver o status morfológico de $\mathrm{t}$-,d- depende também da aquisição de formas verbais irregulares enquanto uma categoria abstrata.

Neste artigo $^{1}$ abordamos a questão da relação entre conhecimento linguístico, variação e aquisição com base em dados de aquisição da flexão variável em nominais e em verbos.

\section{Aquisição de flexão nominal e flexão verbal}

Há diversos aspectos a serem considerados na aquisição da flexão. De um lado a aquisição da morfossintaxe de plural envolve a distinção conceptual de "um" versus "mais de um". Estudos sobre desenvolvimento cognitivo mostram que a distinção conceptual subjacente às representações linguísticas relacionadas a múltiplos indivíduos (nomes no plural, além dos quantificadores) pode estar ausente em crianças na fase prelinguística. Barner et al. (2007), investigando a relação entre a aquisição da morfossintaxe singular-plural e as representações das crianças de distinções entre singular e plural, observaram que crianças de 18 meses adquirindo inglês se comportaram como as de 14 em tarefa para distinguir 1 versus 4 indivíduos, indicando que elas eram capazes de distinguir 3 objetos de 1, mas falharam ao representar quatro objetos como plural ou "mais de um". A mesma situação foi observada para crianças de 20 meses, mesmo quando receberam pistas morfossintáticas explícitas. Somente as crianças de 22 a 24 meses foram bem sucedidas na tarefa com ou sem pista verbal. Dados anotados de relatórios dos pais mostram que muitas das crianças de 24 meses e poucas das crianças com 22 meses produziam formas nominais no plural. Os autores discutem, então, se a aquisição linguística tem algum papel na implementação da distinção conceptual de singular-plural, embora não apresentem uma posição definitiva sobre o assunto.

Outro fator importante envolve a relação entre as marcas

1 Esse trabalho é parte do projeto de pesquisa com o apoio do CNPq, processo no 304056/2007-3 Bolsa de Produtividade em Pesquisa, e apoio da FAPERJ, Bolsa C N E, proces so no $-26 / 102.405 / 2009$ flexionais e outros aspectos da gramática. Ferenz e Prasada (2002) investigaram os fatores que governam o uso de formas de singular e formas de plural dos nomes contáveis em inglês, através de 2 experimentos, aplicados a crianças entre 1;8 e 5;6. Os resultados sugerem que desde o início as crianças parecem usar tanto infor- 
2 Nos estudos de aquisição, as amostras tanto podem ser longitudinais, acompanhando o desenvolvimento de uma ou mais crianças ao longo do tempo, e/ou transversais, constituídas de várias crianças de diferentes idades analisadas em determinado ponto do tempo. Amostras transversais permitem que se observe o comportamento de um número maior de crianças, com consequências na quantidade de dados obtidos, o que constitui um aspecto importante na observação de dados de variação sociolinguística mação morfossintática, semântica ou referencial dos enunciados, na tarefa de aquisição do plural, ao invés de usar apenas uma delas.

Há ainda que se considerar o papel do input a que as crianças estão submetidas. Miller e Smith (2010) mostram que a variabilidade do input pode afetar a compreensão e a produção de formas de plural. Crianças falantes do espanhol chileno diferiram de crianças falantes do espanhol mexicano em tarefas de compreensão e produção devido a diferenças no input a que estão submetidas. No espanhol mexicano a marcação de plural é categórica ao passo que a marcação no espanhol chileno é variável.

Outro aspecto importante diz respeito ao status das formas flexionadas na gramática. Há posições divergentes na literatura sobre a representação e o processamento de formas flexionadas regulares e irregulares (não previstas fonologicamente), que podem ser sumarizadas em duas posições: o modelo único, que engloba o modelo conexionista (PLUNKETT \& MARCHMAN MARCHMANN, 1991 e MACWHINNEY \& LEINBACH, 1991) e o modelo de redes (BYBEE, 1988), e o modelo dual (MARCUS 1996, PRASADA \& PINKER, 1993, CLAHSEN et al. 1992 entre outros). Para o modelo único, o processamento e a representação das formas regulares e irregulares estão relacionados a um único mecanismo associativo, isto é, todas as formas estão igualmente representadas no léxico, não havendo o estabelecimento de uma regra subjacente default que dê conta da flexão regular. As propriedades morfológicas das palavras, como paradigmas e padrões morfológicos, são emergentes das associações estabelecidas entre as palavras relacionadas na representação lexical, uma vez que se postula que o léxico se organiza em redes de conexão lexical e não numa lista não estruturada. A aplicação de uma forma a itens novos e a existência de regularizações são resultantes da inferência do tipo morfológico mais frequente a partir do armazenamento das palavras em redes de conexões lexicais por semelhança sonora e semântica.

Para o modelo dual, as formas flexionais regulares são o resultado de uma regra default e as formas irregulares estão representadas no léxico. A regra default é aplicada quando não é encontrada uma forma representada no léxico (MARCUS, 2000, p. 155). No processo aquisitivo essa postulação é utilizada para explicar regularizações (overgeneralizations) produzidas pelas crianças. Isto é, as regularizações são o resultado da ausência de forma irregular representada no léxico, ativando a aplicação da regra default.

\section{Flexão Nominal e Flexão verbal variável na aquisição}

Os dados discutidos neste artigo foram coletados da Amostra AQUIVAR-PEUL/UFRJ. Trata-se de uma amostra transversal ${ }^{2}$ (crianças de diferentes idades) de fala espontânea de 36 crianças de 
grupos sociais diferentes, definidos em função da renda familiar (até 5 salários mínimos e acima de 20 salários mínimos), nascidas na cidade do Rio de Janeiro, com idades entre 1;9 e 5;0. Dados desta natureza permitem detectar em que medida a produção variável pode estar relacionada a aspectos da variabilidade do input e a aspectos da variabilidade desenvolvimental. Assumimos que a manifestação variável da criança reflete a aquisição de um aspecto da gramática que não é categórico, portanto, é variável, cujo comportamento pode ser explicado pela competição de efeitos/condicionamentos internos da gramática. A aquisição dessas categorias abstratas é gradual. Na medida do possível, os dados de produção subsidiarão a discussão em torno do status da flexão na gramática e do papel do input na aquisição.

Considerando-se que a variabilidade do input, no que diz respeito ao uso variável de formas de plural nominais e verbais, se encontra bastante documentada em diversos trabalhos sobre a comunidade de fala do Rio de Janeiro (NARO, 1981; SCHERRE, 1978, 1988, 1993; NARO \& SCHERRE, 1991, 1993; SCHERRE e NARO, 1997, 1998, 2006), será feita uma breve exposição da variabilidade observada para esta comunidade.

A flexão variável de número/pessoa dos verbos está relacionada com o grau de diferença entre a forma do singular e a forma de plural. Essa diferença é entendida como grau de saliência fônica. Quanto à configuração sintagmática da sentença, esta é entendida em função da posição e da distância do sujeito em relação ao verbo. Além disso, foram analisados conjuntamente fatores extralinguísticos como escolaridade e sexo dos falantes. O efeito observado para estas variáveis é o seguinte: maiores índices de flexão com formas de maior grau de saliência fônica, com sujeitos próximos imediatamente à esquerda do verbo, e com mulheres e falantes com nível de escolaridade mais alto (SCHERRE e NARO, 1997, p. 95-110). Ainda, a presença variável de marcas flexionais nos verbos está relacionada à presença de formas marcadas no contexto anterior, ou seja, há um paralelismo formal tanto no nível da sentença quanto no nível do discurso (SCHERRE e NARO, 1993, p.7-10) e do traço [+humano] do sujeito (SCHERRE e NARO, 1998, p. 48).

Formas flexionadas variáveis de nominais também são influenciadas pelo grau de saliência fônica, pela configuração sintagmática do sintagma nominal, determinando a posição do elemento flexionado no sintagma, pelo paralelismo linguístico (repetição da mesma variante no discurso) nos planos discursivo, oracional e sintagmático e pela escolaridade e sexo dos falantes. Há maior tendência à realização da forma de plural quanto maior a diferença entre forma de singular e plural. Além disso, elementos nominais não-nucleares à esquerda do núcleo tendem a vir marcados, e os núcleos que ocupam a primeira posição do sintagma nominal. Também mulheres e falantes com nível de escolaridade 
mais alto utilizam mais formas de plural (SCHERRE e NARO, 1997, p. 99-110). Quanto ao efeito do paralelismo lingüístico, a presença de marcas precedentes nos três planos considerados (discursivo, oracional e sintagmático) leva à realização de formas flexionadas (SCHERRE, 1993, p. 34-38).

\subsection{Flexão Nominal}

Para o estudo sobre a flexão de número em nominais, foram analisadas as falas de 13 crianças com idades entre 1;11 e 4;11. Foram levantadas 138 ocorrências de nominais com ausência ou presença da marca flexional de plural. Os dados foram submetidos à análise estatística pelo Programa Varbrul ${ }^{3}$. Em função do número de dados, foram realizadas duas rodadas, cada uma, respectivamente, somente com variáveis linguísticas ou variáveis sociais. As variáveis independentes testadas foram: saliência fônica, posição dos elementos no sintagma nominal, presença de forma no plural na fala imediatamente precedente do entrevistador/adulto, sexo e faixa etária. A aplicação foi a ocorrência da marca de plural, uma vez que se trata de processo aquisitivo. Somente a variável faixa etária foi considerada relevante do ponto de vista estatístico (selecionada pelo Varbrul). No entanto, comentaremos também os resultados para as variáveis linguísticas para comparação com os resultados encontrados na comunidade adulta.

Em relação à posição dos elementos no sintagma nominal, as marcas flexionais ocorreram uniformemente tanto em elementos à esquerda quanto à direta do verbo (88\% e $87 \%$, respectivamente) sendo o núcleo menos marcado (39\%). A grande maioria das estruturas consistiu de sintagmas nominais com elementos à esquerda do núcleo ou somente com o núcleo (As minhas colegas brincam na escola - 3;0; Esses dois hominhos deu uma flor para ela- 3;0), com somente 8 ocorrências de elementos depois do núcleo (Meninos, meninas juntos e felizes - 2;1). A emergência de um padrão flexional em função da estrutura e do grau de complexidade do sintagma nominal depende da possibilidade de estruturas maiores e mais complexas serem produzidas, o que não ocorreu nas produções das crianças entre 1;11 e 4;11.

Em relação à saliência fônica, os dados foram classificados somente em 3 níveis de saliência fônica, diferentemente dos 8 níveis dos estudos com adultos (SCHERRE e NARO, 1997, p.100), devido ao fato de que em fase aquisitiva não foi possível observar a ocorrência de todas as possibilidades flexionais do português. A Tabela 1 a seguir apresenta os resultados para saliência fônica.

Pode-se observar que a grande maioria dos itens encontrados na fala das crianças corresponde a formas com plural regular, o que mostra que o plural irregular, isto é, as formas flexionais de maior saliência fônica têm baixa ocorrência na amostra. Isso pode ser uma característica do processo aquisitivo, o que 
poderia significar que o domínio de formas irregulares de plural nominal ocorreria mais tarde no período aquisitivo. No entanto, seria necessária a coleta de mais dados em um número maior de crianças para melhor verificar a situação dos itens com plural irregular. Os dados de plural irregular foram basicamente os itens flor (produzido por uma criança de 1;11), flores (duas ocorrências em crianças de 3;0) , 1 ocorrência de poderes $(4 ; 0)$, pincel (uma ocorrência com criança de 1;11 e uma de 2;01), pincéis (2;11) e sinal $(1 ; 11)$. Todas as ocorrências de itens que terminam em $-S$ foram flexionadas: felizes $(2 ; 01)$, vezes $(2 ; 10,3 ; 0,4 ; 5)$. Como se trata de aquisição, focalizando crianças de diferentes idades, uma hipótese plausível é a de que o efeito do grau de saliência refletirá o da comunidade de fala no final do período aquisitivo. No entanto, este efeito não pode ser plenamente observado com a quantidade de dados coletados em situação de produção espontânea. Essa questão será retomada na seção 4 .

Tabela 1 - Presença de marca de plural em função
do grau de saliência fônica

\begin{tabular}{|l|c|c|c|}
\hline & $\begin{array}{c}\text { Ocorrências/ } \\
\text { Total }\end{array}$ & $\%$ & Peso Relativo \\
\hline Plural Regular & $106 / 132$ & $81 \%$ & .52 \\
\hline Nomes terminados em -L ortográfico & $1 / 4$ & $25 \%$ & .08 \\
\hline Nomes terminados em -R & $3 / 4$ & $75 \%$ & .43 \\
\hline Nomes terminados em $-\mathrm{S}$ & $4 / 4$ & $100 \%$ & - \\
\hline
\end{tabular}

Quanto à presença de forma flexionada na fala precedente do adulto, a diferença não foi significativa do ponto de vista estatístico entre as produções espontâneas $(79 \%)$ e as ancoradas na fala precedente $(85 \%)$.

A Tabela 2 apresenta os resultados para faixa etária, excluídos os dados de flexão categórica (itens terminados em -S), e basicamente mapeia a distribuição dos dados de flexão regular. As crianças foram agrupadas em 3 faixas etárias em função do percentual de formas de plural apresentadas:

Tabela 2 - Presença de marca de plural em função da faixa etária

\begin{tabular}{|c|c|c|c|}
\hline Faixa Etária & Ocorrências/Total & $\%$ & Peso Relativo \\
\hline $1 ; 11-2 ; 01$ & $12 / 20$ & $60 \%$ & .21 \\
\hline $2 ; 06-3 ; 0$ & $37 / 54$ & $69 \%$ & .27 \\
\hline $3 ; 05-4 ; 11$ & $61 / 64$ & $95 \%$ & .78 \\
\hline
\end{tabular}

Considerando que a maioria dos dados corresponde a ocorrências de flexão regular (132 em 138), a tabela acima captura, na verdade, a gradualidade na aquisição da flexão regular. 
A seguir são apresentados os resultados obtidos para os dados de flexão verbal e na seção seguinte são apresentados os comentários sobre os resultados obtidos nos dois estudos.

\subsection{Flexão Verbal}

Os resultados referentes à flexão verbal de $3^{\mathrm{a}}$ pessoa do plural são oriundos do trabalho de Vieira (2006). No estudo de Vieira foi realizado o levantamento das ocorrências de formas verbais de todas as pessoas do discurso e realizadas as respectivas análises. Neste artigo, serão comentados somente os resultados relativos à $3^{\text {a }}$ pessoa do plural. Os dados foram retirados de 17 crianças da AMOSTRA AQUIVAR-PEUL/UFRJ. Os dados também foram quantificados pelo Programa Varbrul.

Foram obtidas 252 ocorrências de $3^{\text {a }}$ pessoa do plural, que foram analisadas em função das seguintes variáveis independentes: posição do sujeito, saliência fônica, traço humano do núcleo do sujeito, tempo verbal, efeito gatilho (presença de forma no plural na fala imediatamente precedente do entrevistador/adulto), marcas do sujeito no nível oracional (paralelismo oracional) e faixa etária. O programa selecionou, na seguinte ordem, as variáveis: efeito gatilho, posição do sujeito, saliência fônica e idade.

Assim como no estudo sobre a flexão nominal, o "efeito gatilho" foi definido no trabalho de Vieira (2006) como a presença de uma forma de plural na fala do adulto direcionada à criança, que precede a fala da criança como em:

a) Presença de plural na fala do adulto

E: "e onde que eles vivem?"

Cr15: "eles vivem num sítio."

b) Ausência de plural na fala do adulto

E: "Não sei, você, é, o que vai contar pra mim? Conta”

Cr17: “O cavalo e o cachorro (es)tavam lá na floresta escura, aí um passarinho (...)"

Os resultados revelaram que a maioria dos dados com forma de $3^{\text {a }}$ pessoa do plural estava ancorada na fala precedente do adulto 66 ocorrências em 67, (99\% de flexão neste contexto), e menor ocorrência de formas de plural quando não havia forma de plural precedente, 76 ocorrências em 185 casos, correspondendo a $41 \%$ e pesos relativos de .99 e .16 , respectivamente.

O efeito observado para as variáveis linguísticas selecionadas corresponde ao mesmo efeito observado para os dados dos adultos da comunidade de fala. Com relação à distância entre sujeito e verbo (Tabela 3), sujeitos imediatamente à esquerda do verbo favoreceram a presença de formas de plural ao passo que sujeitos distantes ou à esquerda do verbo desfavoreceram. Observa-se assim o mesmo efeito observado para a comunidade de fala adulta. 
Já as formas verbais classificadas em função do grau de saliência fônica também revelaram o mesmo condicionamento observado para os adultos, conforme pode ser observado na Tabela 4.

Tabela 3 - Marcas explícitas de plural nos verbos em função da variável presença, posição e distância do sujeito em relação ao verbo

\begin{tabular}{|l|c|c|c|}
\hline Faixa Etária & Ocorrências/Total & $\%$ & Peso Relativo \\
\hline 0 sílaba & $62 / 81$ & 77 & .76 \\
\hline $1-4$ sílabas & $18 / 29$ & 62 & .46 \\
\hline+5 de sílabas & $1 / 4$ & 25 & .17 \\
\hline Posposto & $2 / 11$ & 18 & .19 \\
\hline Zero Próximo & $7 / 10$ & 70 & .63 \\
\hline Zero Distante & $25 / 117$ & 44 & .35 \\
\hline
\end{tabular}

Tabela 4: Marcas explícitas de plural nos verbos em função da variável saliência fônica

\begin{tabular}{|l|c|c|c|}
\hline Saliência Fônica & Ocorrências/Total & $\%$ & Peso Relativo \\
\hline $\begin{array}{l}\text { Nível 1 [- saliente] } \\
\text { Oposição não acentuada }\end{array}$ & $3 / 12$ & 25 & .31 \\
\hline $\begin{array}{l}\text { 1a. sem mudança na vogal } \\
\text { (conhece/conhecem) }\end{array}$ & 36 & 84 & .34 \\
\hline $\begin{array}{l}\text { 1b. com mudança na vogal } \\
\text { (ganha/ganham) }\end{array}$ & $1 / 5$ & 20 & .38 \\
\hline $\begin{array}{l}\text { 1c. acréscimo de segmentos } \\
\text { (diz/dizem) }\end{array}$ & $41 / 56$ & 73 & .77 \\
\hline $\begin{array}{l}\text { Nível 2 [+saliente] } \\
\text { Oposição acentuada }\end{array}$ & $45 / 69$ & 65 & .64 \\
\hline $\begin{array}{l}\text { 2a. mudança da vogal } \\
\text { (tá/tão) }\end{array}$ & $16 / 26$ & 62 & .18 \\
\hline $\begin{array}{l}\text { 2b. acréscimo sem mudança na vogal } \\
\text { (bateu/bateram) }\end{array}$ & & & \\
\hline $\begin{array}{l}\text { 2c. acréscimos, mudanças e formas } \\
\text { supletivas (veio/vieram; é/são) }\end{array}$ & & & \\
\hline
\end{tabular}

Naqueles verbos em que a diferença entre a forma de singular e plural é menor, há a tendência à ausência de marca flexional, e nos outros casos em que a diferença é maior, há uma tendência

4 Outras inversões desta natureza são observadas provavelmente devido à quantidade de dados e sua distribuição em função de todas as variáveis consideradas. mais acentuada à presença. Pelo fato de as posições mais salientes serem mais perceptíveis, a concordância se fará mais evidente nos três últimos níveis em relação à freqüência da presença da marca.

Vale destacar que o nível mais alto da saliência aparece com o peso relativo .18 , um peso relativo baixo quando comparado com os outros níveis e invertido em relação ao valor percentual 
correspondente ${ }^{4}$. Esse valor não pode ser entendido como desfavorecimento, mas como uma inversão resultante do cruzamento desta variável com outras, procedimento do programa estatístico. Tal fato ocorreu no momento em que o programa cruzou este grupo com o efeito gatilho, revelando, então, que a maioria dos verbos com efeito gatilho não pertencem a tal nível de saliência.

Embora não refletindo o efeito da escala de saliência observada para a comunidade de fala, já que ainda não há uma escala crescente, e sim uma polarização entre os níveis + e - salientes, esses resultados revelam a importância da variável no controle da concordância verbal, uma vez que mostram uma etapa do processo aquisitivo, na qual os verbos que apresentam mais marcas de concordância na fala adulta, os quais se enquadram nos níveis mais altos de saliência, são os que mais apresentam percentual de concordância entre as crianças.

Finalmente, a Tabela 5 a seguir apresenta a distribuição das ocorrências em função da faixa etária. Observa-se que a presença de formas de plural aumenta gradativamente em função da faixa etária. As crianças foram agrupadas em faixas etárias:

Tabela 5 - Marcas explícitas de plural nos verbos em função da variável faixa etária

\begin{tabular}{|l|c|c|c|}
\hline Faixa Etária & Ocorrências/Total & $\%$ & Peso Relativo \\
\hline $1 ; 11-2 ; 01$ & $26 / 60$ & 43 & .29 \\
\hline $2 ; 10-3 ; 0$ & $6 / 12$ & 50 & .30 \\
\hline $4 ; 0-4 ; 04$ & $81 / 124$ & 65 & .55 \\
\hline $4 ; 11-5 ; 0$ & $29 / 44$ & 66 & .72 \\
\hline
\end{tabular}

Considerando a possibilidade de as formas flexionadas ancoradas na presença de uma forma de plural na fala precedente do adulto, apresentamos a tabela 6 a seguir que correlaciona as ocorrências classificadas em função do efeito gatilho e faixa etária ${ }^{5}$.

Tabela 6 - Efeito gatilho em função da faixa etária

\begin{tabular}{|c|c|c|c|c|c|c|c|c|c|c|c|}
\hline & \multicolumn{3}{|c|}{$1 ; 11-2 ; 01$} & \multicolumn{3}{|c|}{$2 ; 10-3 ; 0$} & \multicolumn{2}{|c|}{$4 ; 0-4 ; 04$} & \multicolumn{3}{|c|}{$4 ; 11-5 ; 0$} \\
\hline & $\mathrm{N}$ & $\%$ & P.R. & & $\% \quad 1$ & P.R. & $\mathrm{N}$ & P.R. & $\mathrm{N}$ & $\%$ & P.R. \\
\hline Sem gatilho & $7 / 41$ & 17 & .21 & & 25 & .30 & $42 / 85$ & 49.60 & $25 / 39$ & 64 & .70 \\
\hline Com gatilho & $19 / 19$ & 100 & - & & 100 & - & $39 / 39$ & $100-$ & $4 / 5$ & 80 & .84 \\
\hline
\end{tabular}

O efeito gatilho procurou capturar o fato de que as crianças tendem a ancorar ou repetir as formas linguísticas da fala imediatamente precedente do adulto. A ocorrência categórica

5 Esse grupo de fatores também foi selecionado na rodada do Programa Varbrul. da concordância verbal nas faixas iniciais (1;11-2;01 e 2;10-3;0) contrasta com sua baixa ocorrência nas situações em que o verbo não apareceu na fala do adulto. Nesse caso a ocorrência da pre- 
sença da marca de $3^{\mathrm{a}}$ pessoa do plural não pode ser atribuída a um domínio da flexão. Nas faixas etárias com as crianças mais velhas da amostra $(4 ; 0-4 ; 04,4 ; 11-5 ; 0)$ o efeito da presença de um verbo flexionado na fala do entrevistador se assemelha ao observado para as faixas anteriores. No entanto, observa-se, naqueles contextos não ancorados na fala do adulto, um aumento gradual na ocorrência de formas marcadas de $3^{\mathrm{a}}$. do plural, com índices mais próximos aos encontrados para a comunidade de fala para as crianças mais velhas.

Conforme foi observado na Tabela 6 , a presença da forma flexionada de $3^{\mathrm{a}}$ pessoa do plural na fala do entrevistador tende a ser repetida pela criança (efeito gatilho). Assim foi realizada uma rodada somente com as formas de plural produzidas espontaneamente, sem estarem ancoradas na fala do adulto. Foi observado o mesmo efeito apresentado na Tabela 2 , com exceção dos verbos do nível mais alto de saliência $(2 / 12,17 \%, .10)$. Esses resultados confirmam o efeito da saliência fônica, naquele contexto em que pode ser verificado, fora da repetição da fala do entrevistador, exceto em relação ao nível mais alto de saliência. A análise qualitativa dos dados revelou que são todas ocorrências do verbo ser, como nos exemplos abaixo:

c) Cr31: "é aqueles maus que estava....."

Cr31: "Meus padrinhos é o primo das minhas madrinhas"

\section{Discussão}

Os dois estudos revelaram em comum a diferença em termos etários da realização de formas de plural tanto para nominais quanto para verbos. No entanto, não foi possível observar com a mesma clareza o mesmo efeito de variáveis linguísticas nos estudos. Com relação à aquisição de formas de plural de verbos, os resultados apresentados neste artigo apontam para os seguintes aspectos: a) a variação presente nas crianças reflete a natureza variável encontrada na gramática estabilizada dos adultos; b) os condicionamentos da variável são adquiridos gradualmente. Consideramos ainda o fato de nem todos os condicionamentos observados para os adultos terem se mostrado relevantes do ponto de vista estatístico nos dados das crianças, nos dois estudos, como sendo indicativa de que alguns condicionamentos são adquiridos antes de outros.

Como explicar, no entanto, as diferenças observadas em termos aquisitivos para os dados de flexão nominal e os dados de flexão verbal? Isto é, qual a razão para os dados de flexão verbal exibirem efeitos claros de variáveis linguísticas enquanto a mesma situação não foi observada para os dados de flexão nominal? A princípio, essas diferenças poderiam ser atribuídas à quantidade 
de dados obtidos em cada um dos dois levantamentos e a consequente distribuição dos dados nas diversas células resultantes da composição dos diversos fatores de cada variável independente. No entanto, há que se considerar a possibilidade de haver diferença na frequência de ocorrência dos itens nominais de determinado tipo flexional e de formas verbais não só em função da especificidade da amostra, mas também em relação à frequência de ocorrência desses itens na língua. É possível que as formas de flexão irregular de nomes, além de constituírem tipos morfológicos menos frequentes, sejam itens lexicais cuja frequência de ocorrência não é alta, ao passo que as formas verbais podem estar mais disponíveis em termos de ocorrência no input. Além disso, os dados coletados relativos à flexão nominal ocorreram em sintagmas nominais de baixo grau de complexidade, o que poderia significar que a observação/aquisição de condicionamentos como posição do item no sintagma nominal dependa da aquisição de outros aspectos da gramática que possibilitem a produção de estruturas sintáticas mais complexas. Sendo assim, a aquisição de formas verbais flexionadas e os condicionamentos relacionados ao seu uso variável poderiam ser adquiridos antes daqueles relacionados ao uso variável das formas nominais.

Outro aspecto importante diz respeito ao status da variação observada. Trata-se de um processo que se aplica variavelmente a uma forma básica ou da aquisição, representação e realização variável de formas sonoras diferentes de itens lexicais cuja natureza morfológica será revelada ou estabelecida através de um mecanismo associativo de armazenamento do léxico, conforme mencionado na seção 2? Dados de produção espontânea não constituem evidência direta para nenhuma das duas hipóteses. Essas questão foi abordada em Gomes e Gonçalves (2010), utilizando dados experimentais de produção de formas nominais de plural de palavras reais em situação de teste - itens com flexão regular em -s e itens com plural em -is e metafônicos e em pseudopalavras, procurando observar a alternância na produção de formas de plural (chapeús $\sim$ chapeis, animais animaus). $\mathrm{O}$ foco era a alternância do morfema de plural e não a presença ou ausência da marca de plural. Os resultados obtidos para as pseudopalavras indicaram, tanto em crianças quanto em adultos, que não há uma regra default, do tipo "acrescente -s", sendo aplicada toda vez que não existe uma forma irregular representada no léxico. Se assim fosse, na ausência de um padrão esperado para as pseudopalavras, deveria ter havido a predominância da flexão regular, o que não ocorreu para itens terminados nos ditongos decrescentes -éu e -au, realizados majoritariamente com -is.

Huback (2010), em trabalho focalizando a alternância na flexão dos nomes terminados em - ão do português, observou uma tendência de uso de -ões e que este direcionamento está associado a uma interação entre tipo morfológico e frequência 
de ocorrência da forma de plural. Huback interpreta que o efeito de frequência do item é uma evidência de que as palavras são estocadas inteiras no léxico.

Dentro desta perspectiva, a variável saliência fônica poderia ser interpretada como relacionada a padrões morfológicos diferentes e, portanto, o efeito observado para a saliência corresponderia ao efeito da freqüência de tipo morfológico, que poderia também sofrer influência da frequência de ocorrência dos itens lexicais. No entanto, é necessária ainda a obtenção de mais evidências experimentais conjugadas a mais dados coletados em situação de produção espontânea para melhor responder a essa

questão, que se reveste de uma importância muito grande, uma vez que remete ao status da variação na gramática (processual ou representacional?).

\section{Abstract}

Data of spontaneous production from children between 1;11 and 5;0 were collected from AQUIVAR-PEUL/UFRJ Sample and analyzed in face of their character of sociolinguistic variable and as a developmental process. In this paper we discuss the relationship between linguistic knowledge and acquisition, according to some data of acquisition of variable inflexion of nouns and verbs. The results for verb inflexion revealed that the constraints observed for the adult community manifested gradually indicating the gradual acquisition of them. The same situation wasn't

observed for data of noun inflexion. The implications of these results are discussed.

Keywords: noun inflexion; verb inflexion; variation; acquisition.

\section{REFERÊNCIAS}

BARNER, D., THALWITZ, D., WOOD, J., YANG, S-J., CAREY, S. On the relation between the acquisition of singular-plural morphosyntax and the conceptual distinction between one and more than one. Developmental Science, v.3, p. 367-373, 2007.

BOD, R., HAY, J., JANNEDY, S. (eds). Probabilistic Linguistics. Cambridge, Mass, MIT Press, 2003.

BRITAIN, D. Dialect contact, focusing and phonological rule complexity: the koineisation of Fenland English, In C. BORBERG, M. MEYERHOFF, AND S. STRASSEL (ed) A Selection of Papers from 
NWAVE 25. University of Pennsylvania Working Papers in Linguistics, vol. 4, n.1, p. 141-170, 1997.

BYBEE, J. Morphology as lexical organization. In M. Hammond \& M. Noonan (Eds), Theoretical morphology. San Diego, CA: Academic Press, 1988.

CLAHSEN, H., ROTHWEILER, M., \& WOEST, A. Regular and irregular inflection in the acquisition of German noun plurals. Cognition, v.45, p. 225-255, 1992.

DOCHERTY, G.J., FOULKES, P., TILLOTSON, J. \& WATT, D.J.L. On the scope of phonological learning: issues arising from socially structured variation. In Goldstein, L., Whalen, D.H. \& Best, C.T. (eds.) Laboratory Phonology 8. Berlin, Mouton de Gruyter. p. 393421, 2006.

DOCHERTY, G.J. \& FOULKES, P. Speaker, speech, and knowledge of sounds, in Burton-Roberts, N., Carr, P. \& Docherty, G.J. (eds.) Phonological Knowledge: Conceptual and Empirical Issues. Oxford, Oxford University Press. p. 105-129, 2000.

ECKERT, P. Sound change and adolescent social structure. Language in Society, 17, p.183-207, 1988.

FERENZ, K. S. e PRASADA, S. Singular or plural? Children's knowledge of the

factors that determine the appropriate form of count nouns. Journal of Child Language, v. 29, p. 49-70, 2002.

FISCHER, J. Social influence of a linguistic variant. Word, vol. 14, p.47-56, 1958.

FOULKES, P., DOCHERTY, G.J. \& WATT, D.J.L. Phonological variation in child directed speech. Language, vol. 81, 177-206, 2005. GOMES, C. A. e GONÇALVES, C. M. Flexão de número na gramática da criança e na gramática do adulto. Veredas, Juiz de Fora, UFJF, vol. 14, n. 1, p.122-134, 2010.

GUY, G. \& BOYD, S. The development of a morphological class. Language Variation and Change vol 2, p. 1-18, 1990.

HUBACK, A. P. Plurais em -ão no português brasileiro: efeitos de frequência. Revista Linguística, Rio de Janeiro, UFRJ, vol 6, n. 1, p. 9-28, 2010

KERSWILL, P. E. Children, adults, and language change. Language Variation and Change, vol. 8, p. 177-202, 1996.

KERSWILL, P. E. AND WILLIAMS, A.Creating a new town koine: children and language change in Milton Keynes, Language in Society vol. 29, n. 1, p. 65-115, 2000.

KOVAC, C. AND H. ADAMSON (1981). Variation theory and first language acquisition. In D. SANKOFF AND H. CEDERGREN (eds.), Variation Omnibus. Edmonton, Alberta, Linguistic Research, p. 403-410, 1981. 
MACWHINNEY, B., \& LEINBACH, J. Implementations are not conceptualizations: Revising the verb learning model. Cognition, v.29, p.121-157, 1991.

MARCUS, G. F. Children's Overregularization and Its Implications for Cognition. In P. Broeder, \& J. Murre (eds). Models of Language Acquisition: Inductive and deductive approaches. Oxford, Oxford University Press, pp 154-176, 2000.

MARCUS, G. F. Why do children say "breaked”? Current Directions in Psychological Science, v. 5, p.81-85, 1996.

MILLER, K., SCHMITT, C. (2010) Effects of variable input in the acquisition of plural in two dialects of Spanish. Lingua vol. 120, n. 5, p. 1178-1193, 2010.

NARO, A. J. The social and structural dimensions of syntactic change. Language, vol 57, p. 63-98, 1981.

NARO, A. J. e SCHERRE, M. M. P. Variação e Mudança Linguística, Cadernos de Estudos Linguísticos, vol. 20, Campinas, p. 9-16, 1991.

NARO, A. J. e SCHERRE, M. M. P. Duas dimensões do paralelismo formal na concordância de número no português popular do Brasil. Delta, vol 9, n. 1, p 1-14, 1993.

PRASADA, S. \& PINKER, S. Generalizations of regular and irregular morphology. Language and Cognitive Processes, v. 8 , p. 1-56, 1993. PLUNKETT, K., \& MARCHMAN, V. U-shaped learning and frequency effects in a multi-layered perceptron: Implications for child language acquisition. Cognition, v. 38, p. 43-102, 1991.

REID, E. Social and stylistic variation in the speech of children: Some evidence from Edinburgh. In P. Trudgill (ed.), Sociolinguistic Patterns in British English. London, Arnold . p. 158-171, 1978.

ROBERTS, J. Child language variation. The handbook of language variation and change, (ed.) by J. K. CHAMBERS, P. TRUDGILL, AND N. SCHILLING-ESTES, 333-348. Oxford, Blackwell, p. 333348, 2002.

ROBERTS, J. Acquisition of variable rules: $(-t,-d)$ deletion and (ing) production in preschool children. Institute for Research in Cognitive Science (IRCS) Report 96-09. Philadelphia: University of Pennsylvania, 1996.

ROMAINE, S. Postvocalic / $r$ / in Scottish English: Sound change in progress In P. Trudgill (ed.), Sociolinguistic Patterns in British English . Baltimore, MD: University Park Press, p. 144-157, 1978.

SCHERRE, M. M. P. Paralelismo Linguístico. Revista de Estudos da Linguagem, Belo Horizonte, UFMG, vol. 7, n. 2, p. 29-59.

SCHERRE, M. M. P. Reanálise da Concordância Nominal em Português. Tese de doutorado, UFRJ, 1988.

SCHERRE, M. M. P. A Regra de Concordância de Número no Sintagma Nominal em Português. Dissertação de Mestrado, UFRJ, 1978. 
SCHERRE, M M. P. \& NARO, A. J. Mudança sem mudança: a concordância de número no português brasileiro, Scripta, Belo Horizonte, PUCMINAS, vol. 9, n. 18, p 109-131, 2006.

SCHERRE, M. M. P. \& NARO, A. J. Restrições sintáticas e semânticas na determinação do controle da concordância verbal de número em português. Fórum Lingüístico. Universidade Federal de Santa Catarina, Centro de Comunicação e Expressão, Pósgraduação em Lingüística, Florianópolis, Imprensa Universitária. Vol 1, p. 45-71. 1998.

SCHERRE, M. M. P. \& NARO, A. J A concordância de número no português do Brasil: um caso típico de variação inerente. IN HORA, D. da (org) Diversidade lingüística no Brasil, João Pessoa, Idéia, p. 93-114, 1997.

VIEIRA, Márcia C. Pontes. A Emergência do padrão flexional variável da $3^{a}$ pessoa do plural na aquisição do PB como L1. Tese de Mestrado apresentada à Universidade Federal do Rio de Janeiro, 2006.

WEINREICH, Uriel, LABOV, William and HERZOG, Marvin I. (1968) Empirical foundations of a theory of language change. In: LEHMANN, W. P. and MALKIEL, Y. (eds) Directions for historical linguistics: a symposium, Austin, University of Texas Press, p. 95189, 1968. 